\title{
UM MASSACRE SILENCIOSO E ESQUECIDO, UMA GUERRA ENTRE FUZIS E FLECHAS
}

MARCUS A. S. WITTMANN ${ }^{1}$

UFRGS

\section{RESENHA}

VALENTE, Rubens. Os fuzis e as flechas: história de sangue e resistência indígena na ditadura. São Paulo: Companhia das Letras, 2017.518 p.

"Dois grupos indígenas isolados na Amazônia sofreram um massacre por garimpeiros ilegais na região. O número de mortos, incluindo crianças, é incerto"2.

"O ataque efetuado por fazendeiros, jagunços e pistoleiros deixou um saldo de onze indígenas Guarani e Kaiowa feridos e um morto. Até agora ninguém foi preso ou julgado" 3 .

"Apenas neste ano foram contabilizados 118 assassinatos de indígenas, 106 suicídios e 87 óbitos de crianças com menos de cinco anos de idade"4.

"Após um dentista ocupar o cargo, o presidente seguinte da Fundação Nacional do Índio (Funai) foi um general do exército brasileiro"5.

\footnotetext{
${ }^{1}$ Mestre em Antropologia Social pela Universidade Federal do Rio Grande do Sul (PPGAS/UFRGS) é pesquisador associado do Núcleo de Antropologia das Sociedades Indígenas e Tradicionais (NIT/UFRGS) e do Laboratório de Arqueologia e Etnologia (LAE/UFRGS).. E-mail: wittmann.marcus@ gmail.com .

${ }^{2}$ Conforme: < https://brasil.elpais.com/brasil/2017/09/11/politica/1505159891_541386.html >. Acesso em 11 abr. 2018.

${ }^{3}$ Conforme: <https://www.cimi.org.br/2017/06/39670/>. Acesso em 11 abr. 2018.

${ }^{4}$ Conforme: $\langle$ https://www.cimi.org.br/observatorio-da-violencia/relatorio-2016/>. Acesso em 11 abri. 2018.

${ }^{5}$ Conforme: <http://amazoniareal.com.br/indigenas-repudiam-nomeacao-de-general-franklimberg-apresidencia-da-funai/>. Acesso em 11 abr. 2018.
} 
Os relatos acima mencionados poderiam muito bem fazer parte do livro Os fuzis e as flechas: história de sangue e resistência indígena na ditadura, de Rubens Valente. Todavia, e infelizmente, eles narram acontecimentos dos últimos três anos, e não daquela larga noite de vinte e um anos que assolou o Brasil e, principalmente, os povos indígenas.

Em 1964, quando teve início a ditadura civil-militar, nos conta Valente, o governo brasileiro não sabia ao certo quantos indígenas habitavam o território nacional. Suas estimativas, muito abaixo do real, partiam de um desconhecimento e falta de interesse do que significa ser indígena. Atualmente há levantamentos mais precisos sobre o número de grupos indígenas no Brasil e uma concepção mais profunda sobre quem são essas pessoas e sobre suas culturas. Todavia, o que não se sabia naquela época - e ainda pouco ou mal se sabe - é quantos indígenas foram mortos, removidos de suas terras tradicionais, sofreram torturas, foram forçados a trabalhar ou desapareceram durante os anos de chumbo. O livro de Rubens Valente é uma tentativa de trazer essas histórias e relatos sobre esse processo genocida à tona.

O jornalista, autor do livro, teve em mãos um amplo corpo documental sobre o período, constituído em grande parte de documentos até então inéditos. Durante os três anos de pesquisa e escrita (20132015), Rubens Valente foi um dos primeiros a ter acesso a relatórios, autos de processo, cartas, dentre outros documentos confidenciais do exército e da Funai no período ditatorial. Infelizmente nem todos esses documentos inéditos estavam completos, havendo relatos de destruição de muitos relatórios sobre a situação de povos indígenas nesse período, por exemplo. Somam-se a esse material reportagens da época, livros sobre o assunto e entrevistas (muitas delas feitas pelo próprio autor) com personagens dessas histórias. Com tamanho volume de fontes, o livro aborda fatos de diferentes naturezas sobre mais de cem etnias indígenas no território brasileiro durante um período de quase trinta anos iniciando em meados dos anos 1960 e indo até o final dos 1980.

O livro é dividido em vinte e sete capítulos, seguindo uma ordem relativamente cronológica dos fatos, tendo cada um dezenas de notas geralmente referentes às fontes das informações - ao final do livro. Além disso, há um índice remissivo da obra e algumas fotos de personagens e 
fatos citados. Contudo, fazem falta mapas para mostrar a localização de alguns eventos narrados e um corpo imagético mais rico e volumoso.

Os fuzis e as flechas é um livro de difícil leitura. Isso não se deve, muito pelo contrário, ao seu texto fluente, sua narrativa jornalística, factual e cronológica, mas sim devido a uma questão mais mórbida. A cada página, de um total de 386 de texto, lemos sobre dezenas, quando não milhares, de mortes de indígenas, de crianças a adultos, dos mais diversos modos, seja por doenças ou por violência física. Corpos esses que muitas vezes eram deixados na mata sem um funeral ou então jogados em valas comuns. Os nomes da maioria das vítimas foram engolidos pelo tempo e pelos registros oficiais. O relato sobre o sertanista Antônio de Souza Campinas junto aos Tapayuna, enquanto caminhava pela mata com um indígena de nome Tariri procurando sobreviventes de uma epidemia, é emblemático para ilustrar o tom do livro e dos fatos nele narrados:

De repente, Tariri parou. À sua frente havia diversos ossos humanos espalhados. Tariri sentou-se, "pôs as duas mãos na cabeça, depois bateu com a mão direita em cima do coração e nessa altura já estava chorando, olhando para os ossos todos fuçados pelos porcos da mata, lembrando que no meio daqueles ossos estavam os ossos da moça que ia ser sua esposa". Segundo Campinas, o índio lhe disse em língua tapayuna: "Vocês 'civilizados' mataram todos. Tudo acabado" (VALENTE, 2017, p. 61).

Mortes essas causadas não apenas por aqueles que apertaram o gatilho, infectaram - propositalmente ou não - os indígenas com doenças, sobrevoaram aldeias com aviões soltando veneno, mas também por aquelas figuras que assinaram os decretos, as resoluções, as leis e tomaram as decisões sobre essas populações sem nunca terem pisado na floresta ou conhecido essas pessoas das quais o futuro estavam decidindo. Muitos dos cargos de importância na direção da Funai, por exemplo, foram (e ainda são) assumidos por pessoas despreparadas ou até anti-indígenas. O alerta de Antonio Cotrim nos anos 1970 sobre a situação da FUNAl e da política indigenista brasileira é aterradoramente ainda atual: 
Do modo como agimos atualmente as perspectivas são pessimistas; os entraves burocráticos, desperdícios de recursos, desvio de atividades-fins, métodos de trabalho empírico e outros conduzirão essas frentes a participarem de um desastre que a história jamais nos perdoará, tendo sempre como sua principal vítima o índio - além do drama de consciência daqueles que participarem desse triste epílogo que enodoa a imagem do nosso país ante o mundo (COTRIM, s.d. apud VALENTE, 2017, p. 100).

Além das mortes, cada virada de página traz relatos de trabalhos forçados, de usurpações de terra indígenas por fazendeiros ou pelo Estado, de torturas, de estupros, de abusos e espancamentos. É a narrativa de um massacre e de uma guerra silenciosa, presenciada, vista, ouvida e lembrada apenas por alguns sertanistas, indigenistas, antropólogos(as), missionários e indígenas. São relatos de gritos de dor e sofrimento no meio da floresta que só foram escutados pelos homens, mulheres e crianças sobreviventes. Gritos esses que ficaram durante muitos anos trancafiados em arquivos, guardados em relatórios, cartas e diários, armazenados na memória de algumas pessoas. Como escreveu o sertanista Antonio Cotrim para o mal. Rondon: "os mortos nada escutam, para eles a retaguarda já não existe" (COTRIM, s.d. apud VALENTE, 2017, p. 98). Agora esses gritos, vozes e murmúrios voltam a ecoar através das páginas desse livro.

Contudo, umas das críticas que se pode tecer ao livro é que ele não traz, na grande maioria das vezes, as visões e interpretações dos indígenas sobre os fatos narrados, mas sim esses episódios contados pelo olhar branco. O livro apresenta, principalmente, a história de vida e morte de sertanistas e indigenistas da Funai, além dos dramas pelos quais passaram e, em muitos casos, dos traumas e da culpa com a qual ainda vivem pela morte de diversos indígenas. Extermínios esses causados tanto por vontade própria de fazendeiros e por uma política nacional desinteressada, quanto por "erros estratégicos" das frentes de "pacificação", e legítima defesa, em alguns casos. Sendo os principais personagens os sertanistas e indigenistas, aparecendo mais tardiamente os missionários e alguns(mas) antropólogos(as), a narrativa histórica do livro é predominantemente de uma visão branca e masculina. Isso é causado, principalmente, pelo tipo de fontes e documentos acessados 
pelo autor, os quais também possuíam esse enfoque. As mulheres, geralmente indígenas, aparecem em relatos de relacionamentos com homens brancos, de prostituição e estupros. Contudo, de nenhuma maneira isso tira a potência do livro, o qual é um esforço de (re)contar uma história esquecida e silenciada de povos massacrados. Que um dia ainda se ouça e registre as vozes e relatos dos e das sobreviventes.

Em menor número, mas de grande importância, são os relatos sobre como sertanistas e indigenistas da Funai conseguiram salvar, medicar, alimentar e ajudar os povos indígenas. As narrativas expostas no livro deixam claro que, mesmo com um processo histórico de sucateamento e enfraquecimento da Funai e da política indigenista no Brasil, as ações, muitas vezes individuais e contrárias às ordens vindas de cima, impediram que o genocídio indígena no Brasil tenha sido maior.

É somente nas partes finais do livro que aparecem figuras e lideranças indígenas mais emblemáticas. Isso se dá por diferentes fatores, tanto pela maior organização política dos indígenas no final da ditadura, quanto o maior controle do idioma português por eles e um entendimento melhor da situação e contexto político pelo qual o país passava. Deste modo, não apenas surgiam essas lideranças indígenas que batiam mais de frente com a ditadura, quanto esses episódios e pessoas eram registradas em documentos, relatórios oficiais e reportagens de jornais. Entretanto, dentre nomes como Marçal de Souza (o qual tem sua face ilustrando a capa do livro) e Mário Juruna, o texto do livro cala sobre a figura de Ailton Krenak, por exemplo, e sobre o processo de construção da Constituição Federal de 1988, a qual traz um capítulo sobre os direitos dos indígenas, conquistados pela luta desses povos.

O esquecimento e falta de conhecimento sobre a situação indígena durante a ditadura, como bem mostra o livro, se deu tanto pelo registro incerto e contraditório (muitas vezes feito assim propositalmente) do número de mortos, quanto de uma política deliberada de apagamento e acobertamento da situação genocida, através da destruição de relatórios e/ou da simples ação de não tê-los feito na época. Além disso, deve-se ter em mente que o contato com os povos indígenas não foi apenas institucional através do Estado brasileiro - seja pelo braço do Serviço de Proteção aos Índios (SPI), da Funai e/ou do Exército -, mas também por frentes da Igreja, de missionários, da mídia, de pescadores e fazendeiros. 
O que fica muito claro ao lermos esse livro é que o Estado brasileiro, empresas privadas e latifundiários cresceram, se desenvolveram e lucraram, por todas as regiões, às custas de remoções forçadas, maustratos e mortes de indígenas. Os relatos sobre a rodovia Transamazônica, a usina de Itaipu e diferentes estradas federais, construídas durante a ditadura, deixam esse processo muito claro. A construção da usina hidrelétrica de Belo Monte, projetada na ditadura e posta em prática em um período democrático e por um governo dito de esquerda, deixa ainda mais mórbido, triste e desalentador esse processo. Os fatos e dados expostos em Os fuzis e as flechas jogam por água abaixo qualquer justificativa e argumentação sobre o marco temporal ${ }^{6}$ para a delimitação e homologação de terras indígenas.

A Amazônia, o principal foco de ações do Estado brasileiro no período da ditadura, era vista como um "inferno verde" e intocado mesmo sendo habitada por diversos grupos indígenas - que deveria ser colonizada pelo governo, fazendeiros e famílias de diferentes lugares do Brasil. Hoje é o próprio governo e os latifundiários que vêm criando seus desertos verdes. Com o avanço cada vez mais desenfreado da sojicultora e da agropecuária, o Pampa, o Cerrado e a Mata Atlântica vêm se transformando em áreas inóspitas, em desertos de soja e de eucaliptos regados com sangue indígena, erigidos em territórios ancestrais. A ditadura civil-militar iniciada em 1964 pode ter acabado, mas as práticas genocidas contra os povos indígenas ainda ocorrem, desde a chegada dos primeiros europeus no território. Diferentemente do período abordado pelo livro, atualmente há uma maior cobertura da mídia sobre ataques feitos contra indígenas e ações mais diretas contra isso ${ }^{7}$, todavia, a situação continua alarmante.

Os fuzis e as flechas narra a história de um duplo tempo, de dois períodos concomitantes, a longa noite de vinte e um anos de chumbo da ditadura civil-militar que assolou a sociedade brasileira, e o interminável ano de 1500 anos para os povos indígenas. A pergunta feita há tanto

\footnotetext{
${ }^{6}$ Tese jurídica que defende uma interpretação da Constituição Federal de 1988, na qual apenas as terras ocupadas por indígenas a partir desse ano deveriam e poderiam ser reivindicadas.

${ }^{7}$ A Cartografia de Ataques Contra Indígenas (<http://caci.cimi.org.br $\left.>\right)$, desenvolvida pela fundação Rosa Luxemburgo e pelo Armazém Memória, com dados do Conselho Indigenista Missionário (CIMI) e da Comissão Pastoral da Terra (CPT), georreferencia e disponibiliza os dados sobre violência contra povos indígenas no Brasil.
} 
tempo pelo sertanista Cotrim (s.d. apud VALENTE, 2017, p. 99) ainda ecoa, e ainda permanece sem resposta: "Quem não estava preparado para o contato, nós ou eles?".

\section{Referência bibliográfica}

VALENTE, Rubens. Os fuzis e as flechas: história de sangue e resistência indígena na ditadura. São Paulo: Companhia das Letras, 2017.

Recebido em: 22/04/2018 * Aprovado em: 15/12/2018 * Publicado em: 29/12/2018 